\title{
An American Soldier's iPod: Layers of Identity and Situated Listening in Iraq
}

\author{
LISA GILMAN
}

Musical practices permeate the experiences of American troops fighting in the current Iraq war. Music serves many overlapping and sometimes contradictory roles in troops' day-to-day lives, such as providing ways to pass the time, socialize, relax, escape, motivate, process, mourn, remember, forget, and to express a wide range of emotions: pride, fear, joy, boredom, loss, anger. Similar to editors Susan Crafts, Daniel Cavicchi, and Charles Keil of My Music, I consider "musical practices" as all the ways that people engage with music, from playing, recording, and listening, to rejecting it. ${ }^{1}$ In the volume's introduction, George Lipsitz writes:

Musical practices do not 'start' when we pick up an instrument or when we pay attention to what is happening in a given song. We enter a world of music already in progress around us. No less than in Africa, we encounter music everywhere-at the schools and the symphony halls, in the churches and the taverns, on the radio and television. Our musical practices do not blend life and art as thoroughly as they do in some parts of Africa, but they nonetheless function as nodes in a larger network, as complicated and diverse as ways for people to reaffirm old identities and to forge new ones. ${ }^{2}$

Christopher Small offers the term "musicking" to emphasize that "music is not primarily a thing or a collection of things, but an activity in which we engage." He defines the word to include performance, composition, listening, and dancing. ${ }^{3}$ This article is about musicking, specifically, the practice of listening to music. Some members of the American military compose and perform music while deployed to Iraq; almost all listen to music and listen to music a lot, suggesting that this daily engagement with music is an important part of troops' experiences of war. New technological developments enable American troops to listen to music throughout days and nights during both leisure and work time activities, allowing for the ongoing blending of life and art, or as Eric, a white Army medic in his late 20s whom I interviewed on February 26, 2007, put it, "music was huge over there!" Examining troops' musical practice of listening sheds light on the complicated and diverse "ways for people to reaffirm old identities and forge new ones" within the especially demanding context of war. ${ }^{4}$

Identity is an interesting issue in the armed forces because so much emphasis is placed by both those in the upper echelons and those in lower ranks on shared identity. By "identity," I refer to both the ways

This research has been partially funded by the University of Oregon's Office of Research. I owe my gratitude to my colleagues Jonathan Pieslak, Martin Daughtry, and Suzanne Cusick for their compelling explorations of the soundscapes of the Iraq war. Special thanks to Jonathan and Martin for "taking our show on the road" and presenting multiple panels on our overlapping research at the 2007 Society of Ethnomusicology (with Suzanne), the 2008 Pop Conference at the Experience Music Project in Seattle, and the 2008 Music of War conference at Stonehill College. Your presentations and the discussions that ensued have greatly informed this article.

${ }^{1}$ Susan D. Crafts, Daniel Cavicchi, and Charles Keil, My Music (Hanover: Wesleyan University Press, 1993).

${ }^{2}$ George Lipsizt, "We Know What Time It Is," in Microphone Fiends: Youth Music, Youth Culture, ed. Andrew Ross and Tricia Rose (New York: Routledge, 1994), x-xl.

${ }^{3}$ Christopher Small, Music of the Common Tongue: Survival and Celebration in African American Music (Hanover: Wesleyan University Press, 1987), 50.

${ }^{4}$ See also Jonathan Pieslak, Sound Targets: American Soldiers and Music in the Iraq War (Bloomington: Indiana University Press, 2009) and J. Martin Daughtry, “A Symphony of Bullets': Toward a Sonic Ethnography of Contemporary Baghdad.” Paper presented at Music of War: An Interdisciplinary Conference, April 18-19, 2008, Stonehill College, Easton, MA. 
that an individual thinks of himself or herself in relationship to other people and the way that others classify an individual because they perceive or otherwise categorize the person to be associated with specific collectives. The nature of such groups vary tremendously and can be based on ideas about shared gender, culture, race, occupation, family, religion, place, class, interests, abilities, sexuality, musical taste, and so on. ${ }^{5}$ Some identifiers are more rigidly defined (e.g., a member of the U.S. Armed Forces or of a specific unit within), while others are more fluid or abstract (e.g., country music fan). All individuals embody multiple identifiers, some of which are relatively fixed while others are more fluid and dynamic. For a person who is born physically female and considers herself to be gendered female, her gender identity may be relatively fixed throughout her lifetime, though she might move in and out of other social identifiers related to age, occupation, friendship groups, or musical taste. Identification is necessarily tied to differentiation; when people identify together because they feel that they share something, they simultaneously differentiate themselves from those who do not. ${ }^{6}$ Identity is therefore a process and an interpretive act in that people are constantly performing various identities and interpreting their own and others' behaviors based on ideas about identity, ${ }^{7}$ and people frequently code switch as they negotiate their relationships with others. Music can be important in this "doing" of identity: individuals and collectives can use music to construct strong associations in relationship to a collective, and people "can equally use music to locate themselves in idiosyncratic and plural ways." ${ }^{\prime 8}$ Important to this study is that musical taste is often ideologically linked to other forms of identity, such as class, religion, race/ethnicity, or politics.'

The success of the armed forces is contingent upon people identifying with one another, feeling or at least acting together as a unified body. Themes of brotherhood permeate discourse and action and become especially salient during wartime when individuals are responsible for one another's safety. All the branches of the armed forces strategically organize both highly ritualized events and more informal social events that feature music and sometimes dancing, embodied opportunities for performing and experiencing togetherness. Officers encourage their enlisted men and women to socialize to help solidify bonds outside work environments. Given the social isolation of most when stationed on bases in the US or abroad and even more so when deployed to war situations, most turn to others in their units to socialize, fostering feelings of unity across work and leisure times and spaces.

At the same time that unity is emphasized, the identities of men and women in the U.S. armed forces reflect the diversity of the population of the United States more broadly based in class, ethnicity, race, religion, gender, nationality, political perspective, and attitudes towards the war. On a day-by-day basis, troops negotiate these multiple levels of identity at the same time that many operate, draw from, and contribute to broader feelings of a unified collective. Musical practices provide a window into these webs of identity and also highlight ways in which individuals capitalize on a wide range of musical styles in order to meet their multiple and often conflicting needs.

New technologies-individualized listening devices, Internet sites from which one can download music, and companies, such as amazon.com that make it possible to order music quickly and easily from anywhere in the world - significantly increase the availability of different musical styles and the frequency with which people can listen to music. Other technological developments, such as the ability to hook up individualized listening devices to military vehicles' sound systems, further enable musical listening in a

\footnotetext{
${ }^{5}$ Alan Dundes, Interpreting Folklore (Bloomington: Indiana University Press, 1980), 1-19; Harris M. Berger and Giovanna P. Del Negro, Identity and Everyday Life: Essays in the Study of Folklore, Music, and Popular Culture (Middletown: Wesleyan University Press, 2004), 125.

${ }^{6}$ Martin Stokes, "Introduction: Ethnicity, Identity, and Music," Ethnicity, Identity and Music: The Musical Construction of Place, ed. Martin Stokes (Berg Publishers, Oxford, 1997 [1994]), 5; Richard Bauman, "Differential Identity and the Social Base of Folklore," Toward New Perspectives in Folklore, ed. Américo Paredes and Richard Bauman (Austin: University of Texas Press, 1972), 31-41.

${ }^{7}$ Harris M. Berger and Giovanna P. Del Negro, Identity and Everyday Life: Essays in the Study of Folklore, Music, and Popular Culture (Middletown: Wesleyan University Press, 2004), 125.

',Stokes, "Introduction: Ethnicity, Identity, and Music," 3.

${ }^{9}$ See John Connell and Chris Gibson, Sound Tracks: Popular Music, Identity, and Place (New York: Routledge, 2003$), 15$.
} 
wide range of settings. These technological shifts have notably transformed the musical practices of troops in the current American wars in Iraq and Afghanistan from those of previous ones. ${ }^{10}$

The musical listening of troops during deployment resonates with how they and others listen to music in other contexts. Yet, for many, deployment is a mosaic of psychological extremes-heightened levels of duty, fear, exhilaration, friendship, grief, anger, longing, and stifling boredom-with limited outlets for expressing or working through intense and often conflicting emotional states. For many, music during deployment plays an even more important role in day-to-day life than it might in less stressful occupational and living situations. Examining the types of music that troops listen to at different moments, with whom they listen to different types of music, and the meanings and purposes it has for them sheds light on the ways that music is used by individuals in the military in identity formation, bonding, and differentiation as well as ways that individuals use music to contend with the stresses of war.

\section{Method}

Although participant-observation would be the most effective research strategy for examining troops' wartime musical practices, the research for this project is primarily interview-based because of the obvious dangers of war and restrictions on access for non-military personnel. Most of the interviews were conducted in person and lasted around one hour, while some were conducted over the phone. In some cases, I held more than one interview to pursue additional information. I asked people to describe their listening practices as they remembered them, which yielded very different information than would have observing people's practices as they occurred. ${ }^{11}$ In order to protect interviewees' identities and reduce possibilities of them suffering from any repercussions associated with discussing their experiences of war, I refer to all people interviewed either by their first names or pseudonyms depending on an individual's preference.

This article draws primarily from my interviews with eleven individuals who served in the current war in Iraq, Operation Iraq Freedom (OIF). One had been in the Air Force, and ten were in the U.S. Army, some in Active Duty units and others in the Army Reserves or the National Guard. One of these ten was a woman. Given the controversy surrounding this war and the concerns of the leaders of the Armed Forces about national security and about how the war is represented to the public, I have found that the most effective way to establish contacts has been through word-of-mouth. This strategy has been beneficial for establishing a level of rapport at the same time as it shapes the demographics of interviewees. Given that I live in Eugene, Oregon, where Euro-Americans constitute a heavy majority, it follows that those I have interviewed in Eugene have been primarily white. As I continue to do this research, I am strategizing to engage a broader range of individuals. The people I have interviewed therefore do not and are not intended to constitute a representative sample. Rather than providing generalized explanations of people's musical practices, this article explores the very individualized ways that people engage with music both in their private listening and their interactions with others to yield insight on both the role that music plays in individuals' day-to-day lives and into their experiences of war.

The Internet has been especially useful to this project because of the availability of numerous blogs by veterans and the preponderance of video footage of troops' experiences in Iraq available on www.YouTube.com and other websites. It has also been useful for establishing contact with potential people to interview. Feature and documentary films, such as Gunner Palace and Soundtrack to War, and memoirs published by veterans provide further evidence of the integral ways that music listening is an important part of the war experience. ${ }^{12}$

\footnotetext{
${ }^{10}$ See Pieslak, Sound Targets, and Pieslak, "Sound Targets: Music and the War in Iraq," Fournal of Musicological Research 26 (2007): 123-49. For a discussion of musical practices during the Vietnam War, see Lydia M. Fish, 1993. Songs of Americans in the Vietnam War (accessed September 12, 2008) http://faculty.buffalostate.edu/fishlm/folksongs/americansongs.htm, See also Fish 1989.

${ }^{11}$ Cf. Pieslak, Sound Targets.

${ }^{12}$ See especially Colby Buzzell, My War: Killing Time in Iraq (New York: Penguin Putnam, 2005).
} 
Given that the Iraq war has generated much controversy, my motivation for pursuing this research is partly driven by my perception that the polarizing media is largely unconcerned about the real experiences and complicated perspectives of those who are on the ground fighting. My presentation is intended to present the perspectives of the men and women who have been deployed to Iraq rather than engage with political debates regarding the war

\section{Individual Listening and Identity}

New technologies allow for highly individualized listening of music while in Iraq. Many American troops reported that prior to deployment, they prepared for their projected musical needs. Some gathered CDs and many purchased MP3 players with the largest amounts of memory as they prepared musical selections. Once in Iraq, some continued to acquire music by ordering it, receiving gifts from home, purchasing it at stores on bases, downloading when Internet access was available, and trading tracks with others. ${ }^{13}$ The prevalence of individualized listening devices enabled soldiers to select different musical choices based on their individual tastes, listening desires, and psychological needs at different moments. Individual listening occurred throughout the day, in many venues. Troops reported listening while exercising, relaxing, writing letters, reading, sleeping, socializing, working on base, preparing for missions, and sometimes during patrols and missions.

Media attention has focused on the prevalence of heavy metal and hardcore rap genres in the soundscapes of soldiers. ${ }^{14}$ As an example, the documentary film The Soundtrack to War by filmmaker George Gittoes presented interviews with soldiers along with footage of their musical practices to illustrate the wide range of musical styles enjoyed by soldiers and the numerous emotional needs with which music helped them. In Fahrenheit 9/11, filmmaker Michael Moore used some of Gittoes's footage. He selectively chose scenes in which soldiers described listening to songs by metal bands, including Drowning Pool's "Let the Bodies Hit the Floor" and Bloodhound Gang's "The Roof is on Fire," because they associated the songs' violent lyrics and aggressive musical qualities with what they intended to do to the enemy. As the music pounded and soldiers spoke, Moore simultaneously presented scenes of the brutality of war. These selections of Gittoes's footage are also widely available on YouTube and have been included in interviews with Gittoes, reinforcing association between soldiers, violence, and metal. Though these documentary portrayals were accurate, they also do not reflect everyone's experiences; nor do they interrogate the reasons why people select these kinds of music in these contexts. Though Craig, a white Armored Crewman in the U.S. Army I interviewed on August 12, 2008, explained that heavy metal often pounded through his tank's sound system while his unit was conducting missions, Shannon, a white senior Airman in the Air Force, in our interview on February 7, 2007, said, "I don't know if you've seen Fahrenheit 9/11 where they have that scene where those guys are in those tanks and they put on Bloodhound Gang? That's awful. That's not the way people really are." ${ }^{15}$ My research suggests that while heavy metal and hardcore rap genres were pervasive, individuals' playlists tended to be far more diverse. ${ }^{16}$

People I interviewed described listening to a range of genres: rock, rap, modern rock, death metal, reggae, pop, punk, techno, country, R\&B, modern rock, soft rock, tango, classical, soul, blues, and a wide range of bands and artists, including Lynnyrd Skynyrd, Creed, Ani DiFranco, AC/DC, The Dixie Chicks, Tom Waits, Jimi Hendrix, Dave Matthews, Alanis Morisette, Norah Jones, Police, Jay-Z, Wu-Tang, and Frank Sinatra. This partial list reflects the diversity of those serving in the war. That many listen to an eclectic mix of musical styles and artists also indicates the multiple identities of individuals in addition to

\footnotetext{
${ }^{13}$ In a 2006 Rolling Stone magazine article "Soundtrack to the War," Evan Serpick writes that Amazon.com claimed to have shipped "hundreds of thousands of CDs to military bases in the past year" (2006).

${ }^{14}$ I use "heavy metal" and "hard core rap," fully aware that these categories encompass numerous other generic categories, some generally accepted to be distinct and others whose distinctions are contested. I use the terms as an umbrella term to refer to the more aggressive styles associated with metal or rap.

${ }^{15}$ A number of individuals I interviewed explained that they were not allowed to listen to music while on missions, or that whether they did depended on whether the highest ranking individual present was willing to bend the rules.

${ }^{16}$ See Pieslak 2007 and 2009 for a detailed discussion about soldiers listening to heavy metal and rap music in Iraq.
} 
the many different functions that music plays in the moment-to-moment experience of deployment. The eclectic musical listening of soldiers in Iraq also resonates with those of the general U.S. population. Scholars tracing how new technology is impacting listening practices suggest that the possibility of downloading single musical tracks so easily "can make a listener's tastes more flexible as a result of cheap access to new and unexplored musical genres." ${ }^{\prime 7}$

To some extent, veterans interviewed, as do people outside the military, described their musical tastes in relationship to relatively straightforward markers of identity. On July 19, 2006 I interviewed Dave, a thirty-five-year-old African-American veteran, who had been an infantryman in the U.S. Army. He emphasized how much he enjoyed listening to Reggae because his father was originally from Jamaica. Tina, a white woman in her twenties from southern Oregon, served as an Intelligence Analyst in the U.S. Army (Interviewed on March 3, 2008). She identified with country music, a musical taste shared by many in her social group at home. Evan, a college-educated white thirty-one-year-old Scout Helicopter Pilot and officer in the U.S. Army interviewed on October 11, 2006, identified with house music, and Tyson also a white helicopter pilot and officer in the U.S. Army (Interviewed July 24 and August 26, 2006) identified as a dancer and musician interested in all kinds of music. These associations of musical taste with individual markers of identity constitute important ways that individuals construct their own identities and communicate them to others through their musical practices. Yet, these simplified associations of music to single identities do not reflect most people's actual listening practices nor the multiple layers of identities with which most associate. To take one example, though Dave identified strongly as an African-American and explained when we first met how much he enjoyed Reggae, in our interview, he described listening to a much broader selection of music. When I met Dave at various bars while conducting research in Colorado Springs, home of Fort Carson Army Base, he was often socializing with white Eastern European house DJs and went to many of their events. When I asked him what kind of music he enjoyed, he answered, "I love everything, everything that feels good, beats, vocals, all that good stuff. If it hits me, there's no really deep style, you know, I love hip-hop, I love alternative, I love house music, I love it all." Dave's musical practices revealed him to be someone who enjoyed many different types of music and different types of people, thus complicating the more simple connection between his Jamaican roots and appreciation of Reggae. Considering the breadth of his musical listening is indicative of the complexity of how he identified himself in different contexts, which in turn resonates with the role of music in the "doing of identity" of most people I interviewed.

All interviewees described listening to different kinds of music depending on their emotional and social needs at any given moment. Tina described listening to a single country ballad over and over while sleeping to drown out noises and anxiety. At first, she explained that at someone's suggestion, she "bought a soundtrack that was all classical music, I was having trouble sleeping, so I thought that maybe it would help me sleep. But, some of the parts were really like boom! Boom!” The dramatic movements, which she described as reminding her of "war scenes" were less than soothing. She then chose the more reliable country, "any kind of ballad that was really slow and didn't really have any too loud music. Allison Krauss's "When You See Nothing At All" was a really good one, because it's really just kind of low and slow, it's a nice song, and then you're asleep." Dave explained that he would sit down and listen to CDs to relax. He listened to "a lot of Creed because those were the CDs I had." Shannon listened to older punk rock while exercising, and explained, "sometimes when I was really angry or whatever, I'd listen to punk rock, a lot of screaming. That's a good way to vent your frustration cause there's not a lot of ways you can vent your frustration when you're in the military."

Individual listening devices allow people to listen to music individually even when socializing with others. Tina, for example, explained that she and her roommate would chat while they each wore one headphone so that Tina could listen to her favorite country artists while her roommate could listen to her preferred styles of rhythm and blues, jazz, and rap. Their individualized musical listening indicates that the two women identified differently at the same time, even as they became very close friends and relied

${ }^{17}$ Zachary Wallmark, Making Music in the Digital Age: How Technological Developments Shape the Way We Create and Listen to Music (M.A. Thesis, University of Oregon, 2007), 205. 
heavily on one another. Rather than expressing their friendship bonds through shared musical listening, they devised a way to maintain their differential identities while at the same time socializing. ${ }^{18}$

A number of people interviewed also described listening to musical selections that they felt connected them with people back home. A number of men, for example, listened to songs or albums that their wives or girlfriends had given them. At a time when they were physically and emotionally distant from their loved ones, listening to music that they identified with their partners helped them feel connected. In these cases, musical selections had more to do with the identities of their loved ones than the troops themselves, though often, interviewees reported developing a taste for the music as a result. Eric listened to Ani DiFranco because his girlfriend at the time sent him an album. Craig listened to Sarah McLachlan, a favorite of his then girlfriend, now fiancé; and Tina listened to "I'm in a hurry and don't know why," a song by Alabama because it reminded her of her mom, who "doesn't really know how to relax or slow down."

\section{Music as a Motivator}

Many of those I interviewed described listening to music as a motivation that prepared them to go out on patrols and missions. Music as motivation has been depicted in documentaries about the Iraq war, such as Soundtrack to War and Occupation: Dreamland. In these contexts, troops often listened to aggressive musical styles, such as heavy or death metal or "gangsta rap." In Sound Targets: American Soldiers and Music in the Iraq War, Jonathan Pieslak suggested that the timbral elements of these genres and lyrical associations with power, aggression, and excitement makes them especially attractive for this purpose. ${ }^{19}$ Some media reports and portrayals about this use of music, such as the Fahrenheit 9/11 example already discussed, to me depict soldiers as brutes listening to brute music to be even more brutish. The simplified portrayals of soldiers' musical practices can mask the humanity and complexities of the emotional states of the people who are most closely involved and thus affected by the realities of war. It ignores the very real challenges that these individuals face on a day-by-day basis as they engage in often terrifying situations, regardless of their emotional or intellectual states. ${ }^{20}$ Writing about death metal in non-war contexts, Harris M. Berger observes:

It would be far too easy to caricature death metal as merely aggressive music. While anger and aggression are clearly present in death metal, the ethnography of musical sound has shown that musicians, moshing crowds, and listeners come together at events to evoke, explore, and utilize a wide range of related emotions and qualities: anger, rage, aggression, pure and explosive energy, grandeur, depression, lumbering heaviness, confusion, and countless others. ${ }^{21}$

Similarly, my interviews suggest that many listened to aggressive musical genres "to evoke, explore, and utilize a wide range of related emotions and qualities." Or as Craig explained, "even non-brutish guys need to be brutes to survive in certain instances."

In the descriptions by some interviewed for Soundtrack to War and in Jonathan Pieslak's descriptions in "Sound Targets: Music and the War in Iraq," units listened to music together while preparing for missions, contributing to a shared mental state across the group. Pieslak explained that shared music listening could help to focus attention and dispel distractions. ${ }^{22}$ In contrast, when those I interviewed have reported listening to heavy metal or hardcore rap genres to motivate for missions, they usually did so through individual listening devices, suggesting a private emotional engagement. Danny, a white twentyeight-year-old medic with the Army National Guard interviewed on February 9, 2007, explained:

\footnotetext{
${ }^{18}$ Richard Bauman, "Differential Identity and the Social Base of Folklore," Toward New Perspectives in Folklore, ed. Américo Paredes and Richard Bauman (Austin: University of Texas Press, 1972), 31-41.

${ }^{19}$ Pieslak, Sound Targets, 46-57; Pieslak, “Sound Targets,” 127.

${ }^{20}$ Pieslak, Sound Targets, 162-63.

${ }^{21}$ Harris M. Berger, Metal, Rock, and Fazz: Perceptions and the Phenomenology of Musical Experience (Hanover: Wesleyan

University Press, 1999), 271.

${ }^{22}$ Pieslak, "Sound Targets," 123-49; Pieslak, Sound Targets, 55.
} 
It was you and your head and your music. And for me I'd listen to some Jay-Z or something like that or some $\mathrm{Wu}$-Tang that really just got you pumped up, that way when you went out there, you weren't as scared, I guess. A part of you is like, "Yeah, I'm a thug. I'm ready to go. I'm ready to fight."

The way that Danny reported using this music as a motivator yields insight into the complexity of wartime situations where individuals were required to overcome their own opinions and emotions in order to go forth and do what was demanded of them. Music in these cases could be a tool for managing contradictory feelings of confidence, fear, doubt, excitement, duty, and obligation when one's energies had to be directed at the tasks at hand, which required focus and dedication in order to maximize everyone's safety.

While musical styles categorized as heavy metal are connected to power, Robert Walser clarified that many of those attracted to the power in these genres are themselves in relatively powerless positions, either because of age or economics: "metal fans tend mostly to be young because much of metal deals with experiences of powerlessness that may be, to some extent overcome." 23 Tricia Rose similarly writes that "rap music, more than any other contemporary form of black cultural expression, articulates the chasm between black urban lived experience and dominant, "legitimate" (e.g. neoliberal) ideologies regarding equal opportunity and racial inequality. ${ }^{24}$ In the hierarchical structures within which decisions are made in the military, those fighting the war as enlisted men and women are required to be physically powerful in their work at the same time that most have almost no power to choose where they will live, whom they will interact with, what they will do for work, and how/if they will participate in the war. Additionally, they are restricted from expressing their views about their work environments. Danny notes,

And being in a military environment and the rank structure, you can't tell your superior what you really think of them. You know, whether or not they're doing their job correctly, or whether you just don't like them. You can't get in a fight with them. Because they always threatened that you would be brought up on charges, and you would be going to jail and you would get this, that, and the other thing. And they would throw the book at you, and so the anger would just, it would build up. But for me it always ended up not feeling anymore. You go to, I like to say, you just feel numb because you can't be angry, because you can't be happy, you can't be sad. You just don't feel because there's absolutely nothing you can do and in a sense it's kind of like prison because you know, you're waiting for that time when you can go home, but in the meantime, you're just trying to survive.

This combination of real powerlessness and the necessity of being confident and physically dominant draws people to listen to musical styles whose artists are engaging similar negotiations of power and powerlessness as suggested by Walser and Rose. Similarly, Pieslak writing about American soldiers who have recorded rap during the war, suggests that the fantasy element connected to criminality and violence in gangsta rap "is more about stepping outside of oneself in order to handle the realities of war (destruction, heightened alertness, and death)." ${ }^{25}$ And, in an interview with Pieslak on May 1, 2006, CJ Grisham compellingly describes why he listened to aggressive music:

War is so ugly and disgusting, and it's very inhuman. It's an inhuman thing. It's unnatural for people to kill people. It's something that no one should ever have to do, unfortunately,

\footnotetext{
${ }^{23}$ Robert Walser, Running with the Devil: Power, Gender, and Madness in Heavy Metal Music (Hanover: Wesleyan University Press, 1993), 110.

${ }^{24}$ Tricia Rose, Black Noise: Rap Music and Black Culture in Contemporary America (Hanover: Wesleyan University Press, 1994), 102; George Lipsizt, "We Know What Time It Is," Microphone Fiends: Youth Music, Youth Culture, ed. Andrew Ross and Tricia Rose (New York: Routledge, 1994), x-x1.

${ }^{25}$ Pieslak, Sound Targets, 142.
} 
someone does. And we happen to be that someone sometimes. And so listening to music would artificially make you aggressive when you needed to be aggressive. ${ }^{26}$

Craig explained in my interview with him that when his unit first entered Iraq, they had hooked CD players into the sophisticated Bose intercom system that was in their vehicle. As they crossed the burm into Iraq, everyone in his tank was listening to the same music through their headphones under their helmets. He remembered that they listened to the Drowning Pool song, "Let the Bodies Hit the Floor," a favorite of many soldiers in Iraq. When I asked him how this song and others that they listened to that he described as even "heavier" made him feel at the time, he answered, "well, it's a very scary situation, and I ... I compare it to going to the gym, and trying to get pumped up for the physical task that was coming. And trying to maybe make yourself get behind this thing that you have to do, even though you don't know how you feel about it." 27

While some people listened to heavy metal because its aggressiveness could help motivate them, others I interviewed rejected heavy metal precisely because of its association with violence. Eric explained that the first time he pulled a trigger, he was listening to AC/DCs "Back in Black":

Not to say that that song has anything to do with war or killing or anything like that, but something about the tone of the music, I guess, probably is what set me into not wanting to listen, like wanting to find musics that were so detached from any kind of aggressive or warlike, you know, aggressive kind of place in my mind.

He reported that after that experience, he avoided any music that in any way reminded him of death and hated the genre "death metal" just for its name.

\section{Individual Listening and Articulations of Gendered Identities}

Individualized listening can also be an avenue for individuals to express various aspects of their identities either privately or to others, and sometimes can play a role in the negotiations of identities and conflicts. Gender, for example, is an integral identity marker of many musical genres, especially the aggressive musical styles of metal and some rap, and these identity dynamics often intersect with class. The timbral quality, rhythms, lyrics, and the musicians themselves in a lot of heavy metal and hardcore rap recordings are associated with males and a narrowly defined masculinity that resonates with the rough masculinity embraced by many in the military, especially within its lower echelons ${ }^{28}$ Here, it is important to recognize that different branches, units, jobs, and ranks within the military are associated with different articulations of masculinity. Just as Stephen Meyer distinguished between the "rough masculinity" of unskilled laborers in the automotive industry and the "respectable masculinity" that arises from the skilled craftsman's traditions, many of the military jobs requiring the most physicality, danger, and combat are associated with rough masculinity, while those involving less danger and higher levels of education are often associated with "respectable masculinity." 29 Simon J. Bronner who used the term "manliness" in lieu of "rough masculinity" defined it as "being about aggressiveness, sexual prowess, muscular strength, social dominance, and competition." " For those belonging to units where rough masculinity dominates, listening to selections that did not conform to these ideals, even in one's private listening, could lead to jibing and/or ostracization. Danny, who listened to Norah Jones and Alanis Morissette, described people

\footnotetext{
${ }^{26}$ Pieslak, "Sound Targets," 140.

${ }^{27}$ Pieslak, Sound Targets, 185-86.

${ }^{28}$ For example, see Walser Running with the Devil, 108-36; Rose, Black Noise; and Krims, Adam, Rap Music and the Poetics of Identity (Cambridge: Cambridge University Press, 2000). For a discussion of gender in the military, see Burke 2004.

${ }^{29}$ Meyer, Stephen, "Work, Play, and Power: Masculine Culture on the Automotive Shop Floor, 1930-1960," Boys and Their

Toys: Masculinity, Technology, and Class in America, ed. Roger Horowitz (New York: Routledge, 2001), 13-32.

${ }^{30}$ Bronner, Simon J., "Introduction," Manly Traditions: The Folk Roots of American Masculinities, ed. Simon J. Bronner

(Bloomington: Indiana University Press, 2005), xi.
} 
making fun of him, for example, saying, "What, you listen to girl stuff? Like are you gay or something?" He also "got a lot of crap" for listening to Dave Mathews." His friend, Eric described similar experiences:

A lot of people thought I was cheesy, you know. There's this separation between infantrymen and medics. And it's, you know, a lot of my infantry guys would probably harass me for saying this, but there's just this different mentality. They're just as educated as I am, well not all of them, but most of them are. The intelligence level is there, I mean, obviously infantry is, does have the lowest requirement for entrance into the job, whereas medic has the highest, you know so there is that. But for the most part, that's just something you wanted to do so in that, you've got people who like to hunt, people who like to shoot guns, think all that stuff's cool. Where there's me, "I'm just doing it because I don't want to die, I don't want you guys to die, you know." Whereas some of them, it was like playing GI Joe everyday. So they thought I was a little cheesy, you know, something bad would happen and I'd be, "Oh why don't you come back to my room. Let's talk, do a little debrief." I'd turn on some kind of music, and they'd be like, "What's this crap?" "Oh, you know, it's just something I like to do, is listen to music that's mellow, something where you can just sit there and get lost in the words, and forget about it for a couple hours. All of a sudden you find yourself, you've fallen asleep and you've actually been able to rest before the next mission.

Eric expressed that though others in his unit "thought he was a dork," he also proved himself, presumably as a heterosexual man, in other domains, lessening the social stigma associated with his musical taste. He explained:

I do feel that they considered me to be one of them as far as, you know, they saw me do everything that they did. I never backed down from any of the things that they had to do nor did I take any time off that I could have taken or anything like that. So, I worked to earn their respect and whatever, but they still thought I was a dork.

Similarly, Craig was sometimes teased for listening to the Canadian singer songwriter Sarah Mclachlan. He frequently listened to her album Surfacing at night for its calming effect. Though people gave him a hard time, he said that a number of other men in his unit regularly borrowed the CD, indicating that even in contexts where rough masculinity dominates, individuals nevertheless embody more complex articulations of gender: a man can both be a gunner on a tank and listen to a woman's soothing singing. Craig, Eric, Danny, and others I interviewed chose to listen to women artists specifically because they felt these artists were clearly distinct from what they were experiencing. Eric explained that he listened to Ani DiFranco, whose music had previously been unfamiliar to him, because "it was totally different from what I was going through, which was what I was looking for."

Conversely, in the work environments where rough masculinity did not dominate, expressions of hypermasculinity through music listening can be a source of derision. Pilots in the Army, for example, are all officers, and their positions require higher levels of education, training, and specialized skills than do those in the enlisted ranks. The qualities necessary for these jobs are often also perceived as masculine, though not necessarily "manly," such as intelligence, precision, and education. Some pilots I interviewed especially enjoyed varieties of "house" music, and characterized infantrymen as more likely to embrace hypermasculinity through heavy metal and hardcore rap, and some explained that they did not enjoy going to clubs where these music styles dominated.

\section{Group Listening}

In addition to listening to music individually, many opportunities exist for individuals to listen to music in groups. Sometimes, two or more people plugged headphones into a single MP3 or CD player. Other times, individual listening devices or computers were amplified through stereo systems, and 
sometimes music was played over the radio or stereo systems both in non-work and work environments. People described listening to music together in living quarters, outside while playing sports or working out, in work spaces on bases, and through the sound systems of vehicles that are on patrols or missions. Andrew, a white Surgical Technologist and Combat Medic in the U.S. Army in his late twenties, interviewed on February 12, 2008, described listening to music on a stereo in their respective work centers on base. Craig and others in tanks listened to the same music through the vehicle's sound system, and Eric listened to music while sitting in the cab of the ambulance vehicle with its driver during routine patrols.

Unlike most work environments, troops deployed to Iraq are immersed in their occupational environments twenty-four hours a day. When they are not actively working, they are nevertheless confined to their bases or other living arrangements and surrounded by the same people with whom they work. Stanley Parker identifies different patterns of relationships between people's work and leisure time activities depending at least partly on the nature of their work. Someone whose occupational duties feel satisfying and resonate with their interests and ambitions is likely to engage in leisure-time activities more closely related to their work-time activities and to engage in them with co-workers. Those less satisfied or who actively dislike their work may be more likely to engage in activities consciously distinct from work, either with co-workers as a form of shared opposition, or explicitly not with co-workers in order to distance and escape from the work environment. ${ }^{31}$ Kenneth Roberts cautions against putting too much emphasis on people's work in order to determine their leisure pursuits, citing the importance of other aspects of people's lives, such as their familial relations. ${ }^{32}$ For those Americans deployed to Iraq, however, work is everything: it determines their geographic location, their social surroundings, as well as what is available to them as far as mobility and choices of activity during non-work times.

Members of single units are housed together, which means that they are sleeping next to the same people with whom they work. Most have no opportunities to leave bases aside from work activities, and when they do, they are in a hostile environment where opportunities for leisure-time activities that might help them relax or escape their work environments are relatively non-existent. It is also necessary that they get along with others in their units, and they are responsible for one another's safety. Most living arrangements provide limited variety of activities or even spaces within which to move. Shannon, for example, mentioned that exercise was a leisure activity that allowed him to escape temporarily from what he was experiencing. He especially enjoyed running in the Kuwait desert. But even in this open space, he felt a sense of imprisonment, because it was enclosed by a barbed-wire fence. The intensity of this isolation and enclosure is aggravated, especially for those who go out on regular patrols and missions, by the stress of their occupational duties, which combine exhilaration, excitement, fear, boredom, and often seeing and doing things that are emotionally distressful. People working in such intensive situations often need leisure spaces within which they can detach from work, participate in alternate activities, and recuperate.

Depending on the type of living arrangement for units, available leisure pursuits vary. Large bases have Morale, Welfare, and Recreation [MWR] centers that offer a variety of activities and services for troops, including scheduled dance nights featuring different genres of music. ${ }^{33}$ And, the United Service Organizations (USO) organizes tours for troops in the Gulf region, featuring American performing artists and other celebrities and entertainers. Many living quarters are much more limited and provide fewer activities. Those I interviewed described reading, playing video games, exercising, watching movies, playing sports, listening to music, making music, writing letters, and surfing the Internet as the only things they had to do. In addition, it is worth noting that U.S. military regulations for troops serving in Iraq ban the consumption of alcohol and sexual relations outside of marriage. With this paucity of possible

\footnotetext{
${ }^{31}$ Stanley Parker, “Towards a Theory of Work and Leisure," Sociology of Leisure: A Reader, ed. C. Critcher, P. Bramham, and A. Tomlinson (London: E \& FN Spon, 1995), 28-37; see also Stanley Parker, Leisure and Work (London: George Allen \& Unwin, 1983).

${ }^{32}$ Kenneth Roberts, "Work and Its Corollaries," Sociology of Leisure: A Reader, ed. C. Critcher, P. Bramham, and A. Tomlinson (London: E \& FN Spon, 1995), 38-42.

${ }^{33}$ Most of the individuals I interviewed were not on bases with MWR centers. Some went to these bases during breaks, though most did not participate in the dance nights.
} 
activities, music was very important and was especially pervasive because it could be done with other leisure-time activities and could be pursued for individual needs as well as part of social activities.

The organization of work units in the armed forces structures certain identity patterns that shape group listening practices. With respect to gender, for example, men far outnumber women. Percentages of women in each branch of the military differ, with the Air Force having the highest in active duty at 19.7\%, the Marine Corps the lowest with 6.1\%, and the Army and Navy around 14\%. ${ }^{34}$ Combat units are restricted to men; different branches and different rank levels are associated with different articulations of masculinity; and displays of homosexuality are not tolerated. The distribution of people of various ethnic and racial identities varies in different branches, hierarchical strata, and units. For example, whites constitute the highest percentage of Active Duty personnel in the Air Force at $72.3 \%$ while they comprise $61.2 \%$ of the Navy and 62.5 percent of the Army. Blacks constitute around $20 \%$ of the Army, yet only $11.9 \%$ of the Marine Corps. Hispanics, meanwhile, constitute $13.7 \%$ of the Marine Corps, but only around $5.5 \%$ of the Air Force. These fairly general figures are useful for understanding relationships between structural patterns and identity. More detailed demographic information is available on the websites for each branch. ${ }^{35}$ With respect to socio-economic factors, divisions between ranks are associated with class, and these divisions are both spatial and occupational. People of similar rank live together, and stratification within the military relates to class hierarchies within the U.S. population. Those with lower levels of education usually operate at the lower strata of the military. These class/rank divides in the work environment are maintained in living situations where people of similar rank are housed together, and thus also socialize and share music together.

As an illustrative example, here, J.D., a white thirty-one-year-old officer and a pilot in the U.S. Army interviewed on July 24 and August 21, 2006, described relationships between rank, socializing, and musical practices in his unit:

LISA: Were people trading [music] across rank or was it within a given rank?

J.D.: It was probably mostly amongst the pilots with the warrant officers, and enlisted men trading amongst themselves. It wasn't really across the ranks, I don't think. We were all kind of separated in rooms by rank as well. It was more who was in your room or building and stuff like that.

LISA: So, you would tend to socialize more with the people you would be living directly with who were mostly people of the same rank?

J.D.: Yes.

LISA: Okay. And, just out of curiosity, I'm thinking about musical taste, were they mostly white or were there some African Americans or Latinos or other ...

J.D.: All white.

\footnotetext{
${ }^{34}$ These percentages are from May 31, 2006 as reported on the website of Women In Military Service For America Memorial Foundation, Inc, http://www.womensmemorial.org/PDFs/StatsonWIM.pdf (accessed on September 8, 2008).

${ }^{35}$ All demographic information was accessed on the Internet on September 8, 2008: 2007 demographic information for the Army found on the Department of the Army website, Army Demographics FY07 Profile http://www.armyg1.army.mil/HR/docs/demographics/FY07\%20Army\%20Profile.pdf; 2004 information for the Navy was accessed on the Department of the Navy website FY04 Profile of the Navy http://www.armyg1.army.mil/hr/docs/demographics/FY04\%20Navy\%20Profile.pdf; 2004 information for the Marine Corps was found on the United States Marine Corps website FY04 Profile of Marine Corps, http://www.armyg1.army.mil/hR/docs/demographics/FY04\%20Marine\%20Corps\%20Profile.pdf; and the Air Force demographics was found on the United States Air Force website FY03 Air Force Profile, http://www.armyg1.army.mil/hr/docs/demographics/FY03AirForceProfile.pdf. Though I encountered difficulties finding demographics for all four branches for the same year, these numbers are useful for establishing demographic patterns across the branches.
} 
LISA: All white. Was there a difference between enlisted men?

J.D.: As far as race?

LISA: Yeah.

J.D.: Yeah, I guess there was. There were Latinos and blacks within the enlisted rank in my troop. We even have a couple of female enlisted as well, but we don't have any female pilots. Until now, we do, we have Lieutenant [name omitted]. In Iraq, we didn't have any though.

LISA: Were you aware at all, among your enlisted men, were people listening to a variety of different kinds of music or did you even know?

J.D.: I think that rap was more popular among the enlisted side than in the officer rank. Hip hop, whatever.

His description of his unit yielded insights into ways in which race and gender intersected with class in the organization of work and living environments.

Units in Iraq are housed in a wide variety of situations, some in established bases, others in buildings that they had taken over, others in tent cities, and others in make-shift quarters. Within these spaces, individuals often have the autonomy to select where to establish their sleeping quarters. Though all interviewees expressed a sense of bonding with all members in their units, people also explained that they tended to develop stronger bonds and friendships with some individuals with whom they identified based on feelings of shared identity, such as personality, musical taste, ethnicity, language, religion, home, perspective on the war, or gender. Those with closer bonds tended to group together for sleeping arrangements and socializing. As Evan explained:

You try to build a lot of unit cohesiveness because those are the people who you are going to go to war with, you are going to fight side by side with. And, you go along with those people, and if you find some in that group who share your musical interests, that's a bonus.

Sometimes, large numbers of people are given a single space within which they created makeshift walls and other dividers; a few enjoy private quarters or share a space with one or two others. These reorganizations of space into living arrangements often represented social bonds as well as divisions. Tina, for example, described a living situation divided based on gender. Her unit stayed in bays that housed around twelve people. In her bay, the eight women lived in half of it, which was separated from the other half by a curtain where the four men lived. Shannon who was in the Air Force, stayed in a tent where everyone was white. Craig worked as an Armored Crewman in a compact all-male tank unit that he described as "heavily minority," which he elaborated as including "a lot of Mexicans, a lot of AfricanAmericans, one Russian . . . let's see, islanders, probably about ten percent of my company were Dominican, Puerto Rican, Haitian, and Jamaican." He explained that they stayed in cement buildings in which there "were segregated rooms where groups would kind of claim their area, but it's not like, this is our turf, you can't come here, it's more of, this is our room, you know just be respectful of it." Asked on what basis people grouped together, he explained that people who worked closely together often arranged their sleeping areas together and that musical tastes were also important. He explained, "A lot of us worked closely together with each other, so I guess music and backgrounds played a big part in where people stayed." He elaborated that given the linguistic and cultural diversity of his unit, people often aggregated based on shared language and culture, which was often also linked to shared musical tastes. It is important, however, that he also emphasized that there was a lot of interaction between all members in his unit, and that he would move between groups frequently, depending on what music they happened to be listening 
to: "I went back and forth, if it was a song that I liked, I would be with the group, listening. If not, I had my headphones on, writing letters or taking pictures."

Similarly, Andrew explained that people in his unit grouped together based on friendship and work bonds, but also based on cultural identifiers. Here, he describes the ethnic divisions that characterized his unit:

I was in charge of all the lower soldiers, so there were 12 soldiers in that bay. And these guys were, you know, like the black guys in my unit, they kind of moved into their own corner. They had their own music playing all the time very loud, and it bothered a lot of people, so there were dislikings because of music choices and volume. I told them, "hey, get a pair of headphones and you can listen to whatever you want, you know, but everybody else here, you need to have respect."

This example highlights differential identities played out based on race/ethnicity; the black soldiers arranged their sleeping quarters together and listened to music that Andrew and his cohort found invasive, thus contributing to a sonic division between the men. Power dynamics were also evident in this example in which Andrew described his often futile attempts to exert the authority he had over these men by encouraging them to listen to their music through headphones; they, in turn, used music to exercise their power despite their subordinate status.

Similar negotiations of power through music occurred during work-time activities. In situations of shared listening, who gets to choose the musical selections for the group can be the product of various identity dynamics. In some situations, certain individuals are more likely to select music for group listening, sometimes because they have a musical collection that others appreciate, are considered to be especially knowledgeable about music, belong to the majority group, or they may have greater social status or power within the group. In many work environments, military hierarchies were dramatized through the control of soundscapes.

In situations where everyone shared similar rank, the selection of music could be relatively straightforward. Craig, for example, worked on a tank with three other people, all of whom were of similar rank. He explained that either everyone participated in selecting the music or it was left up to the person who had control of the communication system, even if he was the lowest ranking member. In many other situations, the highest-ranking person dominated, replicating military power structures, but also sometimes precipitating power plays and acts of resistance. Here, Andrew describes working in a medical unit:

ANDREW: Well, the surgeon's the main man because they're doing all the, they're the highest-ranking person aside from anesthesia. They're the man, so we have to let them, you know, we can't have our music on. If, for example, my music was playing, it happened several times, they would just be like "turn that off!" They're not used to that kinda music or whatever I'm playing

LISA: Uh-huh

ANDREW: So they have the upper hand in the military, it's rank says all, so you kind of just say, "Okay, sir."

LISA: Um-hm

ANDREW: But, uh, I mean when they weren't in there it was whoever, it was free game for anybody pretty much.

LISA: So would you say that they'd come in and you'd say quickly, "we have to turn this down?" 
ANDREW: Pretty much, yeah, or they'd come in, and we'd rebel. We would usually rebel and just have it playing, and then they would come in and have us turn it off. The worst thing that can happen is the music going off.

LISA: Did you ever leave it on when they said turn it off?

ANDREW: No.

LISA: Yeah...

ANDREW: Because they'll, they'll just make things horrible, and there is a patient there, and that's what matters at that time so, no.

LISA: So your rebellion could only go so far?

ANDREW: So far.

Similar types of dynamics emerged in less formal relationships of power; for example, when asked whether women ever selected the musical choices in his work environment, Andrew could not remember that happening, and Tina did not remember ever having made a selection, nor did she think the other women she worked and lived with usually did either. She attributed this to the women not having laptops, "so it was mostly male music." The reluctance of Tina and other women in her cohort to air music from their playlists could also have been related to being women in a male dominated environment.

\section{Collective Listening, Collective Identities}

Despite the multiple overlapping ways that people identify within the larger group, the success of collective identification in the armed forces is very apparent. Many soldiers I interviewed expressed very strong commitments to serving in the armed forces, often because of their dedication to others in their units. Most explicitly differentiated between their commitment to others in the military generally and their units specifically, and their commitment to policy makers or the U.S. government, which they occasionally criticized. Individuals sometimes negotiated these tensions between their identity and political perspectives and their feelings about the collective through musicking.

Individuals reported listening to music that they did not necessarily like in order to socialize and share with others in their units. In social and work environments where collective listening occurred, people acquiesced to others' musical tastes, and some described developing a taste for styles that they had previously rejected. Veterans interviewed also often described getting to know and/or befriending categories of people that they would not normally outside of the military.

The performances by American popular musicians organized by the USO provided opportunities for soldiers to come together, regardless of whether or not individuals would choose to listen to the genre of music or artist performing in a non-war context. Interviewees described appreciating the artists' efforts to come into a warzone to entertain them and the opportunity to escape their surroundings. Here, Tyson described his excitement upon hearing that Charlie Daniels was going to be in Baghdad:

TYSON: Before we left Baghdad, I'm not a really big country music fan, but Toby Keith was a really nice guy and class act. And so was Charlie Daniels. And I got my picture taken with Charlie Daniels, and I got to see him play live. And that was an awesome show. Charlie Daniels playing live over there! He's a big man. And pretty much, the troops, you know everybody, we found out that Charlie Daniels is going to be in Baghdad, so we're like, "alright everybody, jump in the back of the truck!" And, we all just took off. We all just disappeared for a while. We told the commander, "We'll be back later." And, we drove half way around the airport, which you know, is a pretty big area and found the stage where 
they had set up. And it was just kind of, Charlie Daniels and his little band setting up. And, they were taking pictures out back, Charlie and his group. And he saw us roll up with our Stetsons because we're all cavalry, so we had our cavalry Stetsons on. And, he had a big black cavalry Stetson too. And, he sees us, and he says, "who have we got over there?" We said, "Mr. Daniels, you've got the cavalry over here." And he goes, "How do you like my hat?" He was just a real nice guy, and he gave us a wonderful show, just played all night, and just jammed. They did a lot of his style music, and it was great.

LISA: Were people into it?

TYSON: Everybody was into it that were there. And they weren't just trying to do patriotic songs. They were just doing their show. And I think the soldiers appreciated that more than everything else. It was just them doing their show for us and being the great musicians that they are. Just getting together, jamming. It felt good. It really did.

When I asked whether he felt that the show affected the troops' morale, he answered:

TYSON: Oh, for a little while it does.

LISA: For a little while, yes?

TYSON: Until you realize, until the show is over. You can at least forget for a while, for those two hours that you're in the show, you're engaged in the show. You're not really thinking about, you know, war. You're not thinking about that. You're pretty much focused on the music and on the show and on having fun with your buds.

For Tyson, his personal musical tastes were less important than his appreciation that these artists were willing to travel so far and risk their lives to express their solidarity and to entertain and give the troops a brief respite. His memory of attending these events suggests that being with others listening, watching, feeling, and escaping during the concerts contributed to feelings of identification with the collective.

Music is also used during funerals, becoming part of the formalized collective soundscape of grief and mourning. Eric described the rituals that transpire when an American soldier dies:

ERIC: I'm sure you've seen the pictures ... where the boots and the weapon is stuck down and they hang the Kevlar on top of the weapon, and they hand the person's ID tags. It's kinda like, I don't know what they call it. Anyway, and then, after everything is said and the 21 gun salute and taps is played, taps is, there's some music I can't listen to.

LISA: You can't?

ERIC: Instantly...tears. But, the soldiers walk around by the setup displays of each fallen soldier and salute or whatever, and, uh, I don't know. I guess it makes it, for me, it made, sort of put me too close to death. And I've been so close, I mean, I'd seen lots of Iraqis killed. And I've seen lots of my guys killed, so ... I guess by going or not going, I was distancing myself from the ultimate payment of whatever we were there for.

In this case, the use of music for shared mourning of a fallen soldier did not evoke the desired emotion. Rather than feeling a sense of bonding, communitas, the song in the ritual acted to separate him from the whole, it evoked feelings of anger, sadness, resentment, and hypocrisy. The music "taps" was linked not just to his memory of war, but to the way he felt in and about the war.

Eric also described especially intense moments in Iraq as being times when there was "no music": suggesting that music was such a regular part of his daily life, that when things were especially agitated, the 
music stopped. He described a really difficult day when there were many injuries, and three were killed in action:

There was nothing. At least nothing that I remember. I can't imagine that somebody necessarily would have turned off the music. I just don't remember anything . . . . All I can remember about that is silence. Absolute silence.

Compelled by Eric's description of silence, I asked Andrew whether he remembered moments of silence. He answered:

Um, there are probably a few thousand moments where something traumatic has happened you're just like, "wow." I had a couple of my buddies that got shot and they were right next to me. And two of them, there were three of them that got shot and two of them didn't make it. And I was there, you know, in your mind, everything just froze. You know, and you can't hear anything, it was probably from the trauma of it. You know, and also the blast, there was an RPG that hit nearby, and through your head you just freeze for a couple seconds. And then I'm a medic so my automatic reaction is I'm supposed to get up, so I did everything I could and they didn't make it. I had one of them alive for a good twenty minutes doing CPR, but he didn't make it. And then you question yourself, if it was your fault or whatever. But, it's it's, I don't know, there's definitely and then in the OR when I was there, something would be playing and a soldier would die and even though the music's playing in the background, kinda everything just kinda shimmers out and you're just like you're just drained. You know. That trauma definitely drains you. Or that moment just takes everything out of you and you're just like wow. You really you're just in your thoughts the next thought is what the fuck am I doing here, you know.

Music for Andrew and Eric resonated with a sense of normalcy even within the chaos of war. When it got too chaotic, the music stopped.

\section{Conclusion}

When I began this research, I anticipated that if I approached members of the U.S. military explaining that I was interested in discussing what kinds of music they listened to during their deployment(s), they would probably respond by questioning why I wanted to talk about something so mundane when they had experienced something so profound. Instead, what I found over and over is that for everyone I have approached thus far, music immediately resonated as something very prominent and important "over there." Sound dominates the visceral experience of war. Martin Daughtry poignantly illustrates this reality in his examination of how American soldiers and Iraqi civilians develop a sophisticated understanding of what is occurring around them through their interpretations of the sounds of war, which include different types of rifles shots, explosives, vehicles, cries, beatings, and silence. ${ }^{36}$ Troops operating within this din are drawn to music because it can help move them into the state of mind necessary for contributing to it or alternatively for escaping.

Examining the musicking of some who have participated in fighting this war reveals something about the day-to-day experiences of deployment for individuals, each of whom felt and interpreted the war in highly personalized ways. Yet, deployment is, by its nature, social: troops are in constant physical and emotional engagement with others, sometimes of their choosing and often not, whether it be peers within units, those in different ranks, or "the enemy." Music becomes an important avenue for creating and solidifying bonds and sometimes articulating difference and instigating conflict either within units or against "the enemy," as in Jonathan Pieslak's description of how the U.S. military uses music as a

\footnotetext{
${ }^{36}$ Daughtry, “A Symphony of Bullets.”
} 
psychological tactic by blasting the enemy ${ }^{37}$ or in interrogations ${ }^{38}$ and Suzanne Cusick's compelling research on the use of music in detention camps." ${ }^{39}$

Within an environment where personal freedoms are few and where emotional needs are many, music can play an especially powerful role because individual playlists can be very personalized and the act of listening so personal. The possibility of listening to music through individualized listening devices, accessing a multitude of musical selections at any given moment, and the possibility of listening in a wide range of settings allow troops to capitalize on music as they attempt to meet their various needs. Listening to music can play a role in helping individuals stay grounded by connecting their memories of self outside the war environment with their perceptions of self within the war situation. Music can serve as an avenue for expressing multiple identities, sometimes as public expressions and other times as private meditations. By listening together or listening to music that they associate with friends, loved-ones, and particular places, troops can share and connect with others: those who are with them, those whom they have lost, and those far away whom they hope to see again.

\footnotetext{
${ }^{37}$ See Lane DeGregory, “Iraq 'n’ Roll,” St. Petersburg Times, 21, November, 2004.

${ }^{38}$ Pieslak, Sound Targets, 78-99.

${ }^{39}$ Suzanne G. Cusick, "'You are in a place that is out of the world. . .' Music in the Detention Camps of the Global War on Terror," Fournal of the Society for American Music 2 (2008): 1-26.
} 